\title{
Challenges of Urological Oncology for Cure of Cancer
}

In spite of several differences between the urological cancers, all of them demand an early diagnosis. With the exception of malignancies of the testes, only urological tumors which are confined to the organs may be cured by a surgical approach. For small tumors of the kidneys and the bladder (and also for tumors of a residual testis) organ-preserving operating techniques have been established. For larger or infiltrating tumors, loss of the organ is inevitable. The lymph node dissection which is performed by extirpation of an organ in tumors of the kidney, bladder or prostate is only of diagnostic but not of curative value.

Tumor of the Testes. An analysis of the causes of death, which was performed in Germany [1], shows four reasons for negative events: tumor progression despite adequate therapy (29\%); inadequate treatment $(25 \%)$; lack of patient's compliance (16\%); toxicity/complication of treatment $(15 \%)$.

The International Germ Cell Cancer Collaborative Group (IGCCCG) excellently identified prognostic groups in using tumor markers, tumor burden and tumor localization. An average or poor prognosis demands that the patients are treated in clinical trials evaluating dose-escalating or high-dose chemotherapy. The adequate information on the disease is the beginning of an appropriate treatment. Advanced tumors should be treated at centers which are experienced in chemotherapy and which are able to appropriately perform resections of residual tumors if indicated.

The following questions lead towards the future:

- Which role does lymphadenectomy play in clinical stage II if chemotherapy is associated with the well-known excellent cure rates?

- Which patients benefit from a resection of a residual tumor?

- Will there be any new chemotherapeutics, which may cure advanced tumors or may have less negative side effects?

- How does treatment influence fertility and sexuality many years after treatment?

Bladder Carcinoma. MVAC (Methotrexate, Vinblastine, Adriamycin, Cisplatin) has been the gold standard for adjuvant, neoadjuvant and palliative indications in the treatment of bladder cancer for 13 years. Now it is evident that this disease is not curable if metastases to other organs are present: $13 \%$ of complete remissions can be expected to last longer than 1 year [2].
As MVAC/MVEC ( $\mathrm{E}=$ Epirubicin $)$ is a highly toxic and userunfriendly combination, it is our goal to replace this 'gold standard' of chemotherapy for the urothelium carcinoma. In an international clinical trial with 400 patients showing measurable lesions, which was completed only a few months ago, MVEC was compared to a combination of cisplatin and gemcitabine. With very good participation of German urologists the patient recruitment was completed earlier than expected, so that the analysis of data may be performed soon.

MVAC has also been used in neoadjuvant treatment regimens in order to preserve the bladder. The 10-year results of 111 patients show that this aim has primarily not been reached in half of the patients [3]. If it was possible to preserve the bladder, the risk of developing a life-threatening recurrence in the later course was relatively high. The urological approach of a locally advanced and not metastasized urothelium cancer of the bladder is radical cystectomy with bladder replacement, which has only mild adverse effects on the quality of life.

For patients with cystectomy and positive lymph nodes the $\mathrm{pN}$ category determines the future therapeutic approach. $\mathrm{pN} 1$ patients benefit clearly from adjuvant chemotherapy. As radical cystectomy alone cures only every 4 th to 5 th patient, the probability of survival rises to about $50 \%$ with adjuvant chemotherapy [4].

Renal Cell Carcinoma. This is a rather rare tumor which is associated with an emotional connotation, and it puts great demands on the urologist. Up until today the industry offers a vaccination which does not have a proven benefit. In spite of that, physicians apply this treatment for the adjuvant and palliative treatment and burden the medication budget.

Also interferon-alpha (IFN- $\alpha$ ) and interleukin 2 (IL-2) are applied outside of clinical trials with an immense financial effort, although the available data are unsatisfactory. Single, formally correct clinical trials, comparing prospective studies versus 'null arm', could not prove prolongation of life in unselected patients. In spite of these facts the health insurances are charged with treatment costs of up to 100,000 German Marks yearly. This situation shows the problems of oncological clinical research in Germany. To crown it all, interleukin is offered as an inhalative - which results in higher costs without more benefit. IFN- $\alpha$ and IL- 2 are permitted for the therapy of

\begin{tabular}{ll}
\hline KARGER & @ 2000 S. Karger GmbH, Freiburg \\
$\begin{array}{l}\text { Fax }+497614520714 \\
\begin{array}{l}\text { E-mail Information@Karger.de } \\
\text { www.karger.com }\end{array}\end{array}$ & $\begin{array}{l}\text { Accessible online at: } \\
\text { www.karger.com/journals/onk }\end{array}$
\end{tabular}


metastatic renal cell carcinoma, though IL-2 is permitted only for i.v. application. 5-Fluorouracil (5-FU), part of the relatively well examined so-called Atzpodim scheme which is widely accepted throughout Germany, is not permitted for the treatment.

In Germany a national tumor project for renal cell carcinoma (NTP-N) has been established, so that this combination can be compared with 'null arm' in non-randomized therapyoptimizing trials.

Cancer of the Prostate. This tumor remains the main urological problem. Up to now we cannot differentiate with the necessary certainty between the clinically relevant cancer and the insignificant tumor. This fact calls for molecular-biological research. The controversial relevance of screening, the overall high mean age of the patients, and the competition of local treatment approaches have to be discussed additionally. The old-fashioned screening program of the public health insurance has to be adjusted to modern scientific knowledge as soon as possible. The PSA-screening has to be included cost-effectively into this program, so that a 'gamble of millions with low chances to win' turns into a useful measure of health promotion. The resulting higher costs have to be compensated by strict definition of risk groups. We cannot wait with this measures until the three active, prospectively randomized clinical screening trials will be completed (ERSPC in Europe, PCLO and PIVOT in the USA). The side effects associated with long-term hormonal treatment (osteoporosis, muscle atrophy, anemia) have stimulated the discussion on immediate or intermittent androgen blockage. Nevertheless, there are some results from clinical trials in the UK and the USA which implicate that an immediate initial therapy and maximal androgen blockage in patients with metastases and low tumor burden is indicated. The minor differences between the defined patient groups lead to the question whether these findings are statistically significant and clinically relevant. The open questions, which have to be answered in national or European projects, concern the efficacy and cost-effectiveness of radical prostatectomy, external high-voltage radiation, and interstitial radiation therapy. Even against the will of the keeper of the 'Holy Grail of Biometrics' a nonrandomized comparison may improve our knowledge under certain circumstances. Specialized associations, professional organizations, the 'Deutsche Krebshilfe' and the German Cancer Foundation will have to recognize and solve the problems which are of the patient's concern without keeping their own interests in mind.

L. Weißbach, Berlin

\section{References}

1 Köhrmann KU, Albers P, Hartmann M, Heidenreich A, Krege S, Walz P, Weber A, Alken P: Management analysis of patients who died of germ cell tumors. J Urol 1999;suppl 161:181. AUA Abstract No. 697.

2 Loehrer PJ, Einhorn LH, Elson PJ, Crawford ED, Kuebler P, Tannock I, Raghavan D, Stuart-Harris R, Sarosdy MF, Lowe BA: A randomized comparison of cisplatin alone or in combination with methotrexate, vinblastine, and doxorubicin in patients with metastastic urothelial carcinoma: A cooperative group study. J Clin Oncol 1992;10:1066-1073.

3 Herr HW, Bajorin DF, Scher HI: Neoadjuvant chemotherapy and bladder-sparing surgery for invasive bladder cancer: Ten-year outcome. J Clin Oncol 1998;16:1298-1301.

4 Stöckle M, Wellek S, Meyenburg W, Voges GE, Fischer U, Gertenbach U, Thüroff JW, Huber C, Hohenfellner R: Radical cystectomy with or without adjuvant polychemotherapy for non-organ-confined transitional cell carcinoma of the urinary bladder: Prognostic impact of lymph node involvement. Urology 1996;48:868-874. 